\title{
Genotoxic Effects Induced by Fotemustine and Vinorelbine in Human Lymphocytes
}

\author{
Serap Çelikler*, Rahmi Bilaloğlu, and Nilüfer Aydemir \\ Uludağ University, Science and Art Faculty, Biology Department, Gorukle, Bursa 16059, \\ Turkey. Fax: +90 224 4428136. E-mail: scelikler@uludag.edu.tr \\ * Author for correspondence and reprint requests \\ Z. Naturforsch. 61 c, 903-910 (2006); received January 23/April 12, 2006
}

The aim of this study was to investigate the in vitro genotoxic effects of the anticancer drugs fotemustine and vinorelbine on human lymphocytes and to determine individual and sex-related responses to these drugs. Fotemustine is a DNA-alkylating drug while vinorelbine is a semi-synthetic Vinca alkaloid. The study was carried out with twenty independent healthy donors for each drug. We have tested the ability of these drugs to induce chromosome aberrations (CAs) and sister chromatid exchanges (SCEs) as well as effect on the mitotic index (MI) in cultured human lymphocytes. Fotemustine was shown to induce CAs and SCEs at all concentrations tested $(2,4$ and $8 \mu \mathrm{g} / \mathrm{ml})$ in a dose-dependent manner. Additionally it also decreased the mitotic index in a similar dose-dependent manner. Vinorelbine had no effect on structural CAs, but it significantly increased the numerical CAs at all doses tested $(0.5,1$ and $2 \mu \mathrm{g} / \mathrm{ml}$ ). Vinorelbine also induced SCE events and increased the MI values.

Two-way analyses of variance were used to compare the individual and gender-related susceptibilities to fotemustine and vinorelbine with respect to the CA, SCE and MI values. The results indicated that individuals in fotemustine treatment groups showed different genotoxic responses with respect to $\mathrm{CA}$ and SCE induction and additional findings indicated a gender-specific response in this group. Individuals in the vinorelbine test group also exhibited statistically significant numerical CA, SCE and MI responses to vinorelbine. A statistically significant gender-related SCE response to this drug was also evident. This study indicates that these drugs have potentially harmful effects on human health.

Key words: Fotemustine, Vinorelbine (Navelbine), Genotoxicity

\section{Introduction}

Fotemustine is a DNA-alkylating 2-chloroethylsubstituted $N$-nitrosourea (CENU) drug (Vermeulen et al., 1998). Among antitumour agents, nitrosoureas belong to an extremely active class of alkylating compounds that have widespread clinical application in the treatment of brain tumours, melanomas and various leukemias (Winum et al., 2003). The nitrosoureas induce DNA interstrand cross-links starting with a carbonium ion attack at the $\mathrm{O}^{6}$-position of the guanine (Vermeulen et al., 1998; Gander et al., 1999). There is a good correlation between the number of interstrand cross-links and the cyto- and geno-toxicity of nitrosoureas (Marzolini et al., 1998; Gander et al., 1999). In general, alkylating agents are known to cause a number of biological effects in living organisms including mutation induction, carcinogenesis, cell death, chromosome damage biosynthetic pathway inhibition, cell cycle arrest and teratogenicity (Margison and Santibanez-Koref, 2002). Previously, Ashby et al. (1993) have shown that fotemustine is a basepair mutagen to Salmonella. Additionally, it was also observed in this study that fotemustine is a somatic and germ cell mutagen to Drosophila. Fotemustine also had a potent clastogenic effect in mouse bone marrow cells in vivo, following either oral gavage or intraperitoneal injection in that study (Ashby et al., 1993). However, to our knowledge, no studies have been performed regarding the genotoxic effects of fotemustine on human lymphocytes in vitro.

Vinca alkaloids, including the natural products vincristine (VCR) and vinblastine (VBL) and the semi-synthetic derivatives vindesine (VDS) and vinorelbine (Navelbine, VRB), are antimitotic drugs that have been widely used in the treatment of cancer for more than 30 years. In spite of being chemically related, these mitotic spindle poisons exhibit significant differences concerning cytotoxicity, as well as antitumour activity (Zhou and Rahmani, 1992). In VRB the catharantine moiety contains an eight-membered ring in place of the 
nine-membered ring that is present in all naturally occurring members of the VBL group (Ngan et al., 2001; Gonzalez-Cid et al., 1997). It is effective in non-small cell lung cancer, metastatic breast cancer, and ovarian cancer, head and neck cancer, melanoma, non-Hodgkin's lymphomas and Hodgkin's disease and shows promise in the treatment of esophageal cancer and prostatic carcinoma (Bunn and Kelly, 1998).

The mechanism of the Vinca alkaloids is known to involve depolymerization of spindle microtubules and induction of paracrystalline tubulin Vinca alkaloid arrays. Similar to the other Vinca alkaloids, VRB binds tubulin, in effect, negating assembly/disassembly of microtubules by inhibiting tubulin polymerization (Gonzalez-Cid et al., 1997).

The effects caused by the Vinca alkaloids in various in vitro and in vivo experimental systems point to a significant aneuploidogenic activity of VCR, VBL and VRB as well as the lesser ability of these chemicals presented with regards of the inducement of clastogenic events. Tiburi et al. (2002) have shown VCR, VBL and VRB to be recombinagenically potent using Drosophila somatic mutation and recombination tests (SMART) implying a significant genotoxicity of the chemicals. An effect on the proliferative activity induced by VRB was also demonstrated in that the MI (mitotic index) in different normal and isolated lymphocyte sub-populations was significantly increased (Gonzalez-Cid et al., 1997). Moreover, to compare the aneugenic effect of VRB and VCR, a micronuclei (MN) test was used in cultured human lymphocytes using the cytokinesis block method. Both chemicals increased the MN frequency when rates were compared to a negative control (Gonzalez-Cid et al., 1999). In the present work, we have examined the induction of CAs (chromosome aberrations) and SCEs (sister chromatid exchanges) in vitro by fotemustine and vinorelbine using lymphocytes. Similarly, the effect of these drugs on MI under like conditions was also measured.

In recent years interindividual differences in drugs and toxicant reactions have received significant emphasis (Ingelman-Sundberg, 2001). In particular, gender-specific toxicant response is a naturally important subset in predicting overall risk factors of toxicant exposure on humans (Aldridge et al., 2003). Thus, we have tried to investigate the interindividual and gender-specific differences in genotoxic response to fotemustine and vinorelbine in relatively larger donor groups (20 donors for each drug).

\section{Materials and Methods}

\section{Chemicals}

Fotemustine (muphoran, CAS No. 92118-27-9) and vinorelbine (navelbine, CAS No. 125317-39-7) were kindly provided by Department of Radiation Oncology, Faculty of Medicine, Uludağ University, 5-Bromodeoxyuridine (BrdU) was purchased from Sigma and mitomycine-C from Kyowa (Hakko, Japan), respectively.

\section{Lymphocyte cultures and cell harvesting}

Heparinized peripheral blood used in all experiments was obtained from 20 healthy, non-smoking donors (for fotemustine 8 males and 12 females, age: 18-34; for vinorelbine 6 males and 14 females, age: 19-40) for each drug with two replicates, independently. The cultures were set up by adding $0.3 \mathrm{ml}$ of whole blood to RPMI 1640 medium (10X, Sigma) supplemented with $20 \%$ fetal calf serum (Biochrom AG), $100 \mathrm{IU} / \mathrm{ml}$ penicillin, $100 \mu \mathrm{g} / \mathrm{ml}$ streptomycin (Biological Industries), $0.5 \mathrm{mg} / \mathrm{ml} \mathrm{L-glutamine}$ and $6 \mu \mathrm{g} / \mathrm{ml}$ phytohemagglutinin (PHA-L; Biochrom AG). The whole blood cultures for all treatments of each donor were done as two replicates. We have tested several doses of fotemustine $(25,20,15,10,7.5,5,2$ and $0.5 \mu \mathrm{g} / \mathrm{ml}$ ) and have also tested several doses of vinorelbine $(15,10,7.5,5,2$ and $0.5 \mu \mathrm{g} / \mathrm{ml})$ prior to settling upon the doses used in this study. From these preliminary studies, we have chosen the 2, 4 and $8 \mu \mathrm{g} / \mathrm{ml}$ doses for fotemustine and the $0.5,1$ and $2 \mu \mathrm{g} / \mathrm{ml}$ doses for vinorelbine. Lymphocytes were incubated at $37^{\circ} \mathrm{C}$ for $72 \mathrm{~h}$. As negative and positive controls, distilled water and mitomycineC $(0.25 \mu \mathrm{g} / \mathrm{ml})$ were used, respectively. Fotemustine, vinorelbine and mitomycine-C (MMC) were dissolved in sterile, distilled water and drug solutions were prepared immediately before use, to avoid degradation of the drugs. The cells were treated with fotemustine and vinorelbine for $24 \mathrm{~h}$ prior to harvest. Cultures for SCE analyses were incubated in the dark in the presence of $10 \mu \mathrm{g} / \mathrm{ml}$ 5-bromodeoxyuridine. Metaphases were obtained by adding colcemid $(0.2 \mu \mathrm{g} / \mathrm{ml}$ final concentration; Sigma) $2 \mathrm{~h}$ prior to harvest.

Cell harvesting and slide preparation were performed according to Sbrana et al. (1993). To visu- 
alize CAs, slides were stained with $5 \%$ aqueous Giemsa solution for $15 \mathrm{~min}$. Slides to be used for analysis of SCEs were stained using a modified fluorescence plus Giemsa (FPG) method (Parry and Wolf, 1974). 100 metaphases per treatment were analyzed for the presence of CAs and 30 metaphases were counted for SCEs (Bolzan and Bianchi, 2002). The MI was estimated by counting 1000 cells for each treatment and replicate.

\section{Statistical analysis}

The frequencies of CAs and SCEs in treated cultures were compared by use of one-way analysis of variance (ANOVA) and Tukey honest significant difference (HSD) tests with $95 \%$ confidence intervals. Dose-response relationships were determined by regression analyses.

The individual susceptibility to fotemustine and vinorelbine was determined by two-way analysis of variance (MANOVA) and Tukey HSD tests. These analyses were carried out with the commercial software programs SPSS 11.5 and Statistica 6.0 , respectively.

\section{Results}

The results of the CA analysis and MI values induced by fotemustine in lymphocyte cultures are shown in Tables. As seen in Tables I and II, fotemustine significantly increased CAs when gap and pulverized metaphase were both included and excluded compared with the negative control group $(p<0.0005)$. This effect of fotemustine was dosedependent (for the total CAs: $r=0.879, p<0.001$, and for the total CAs excluding gaps and pulverizations: $r=0.890, p<0.001)$. Chromatid breaks, iso-chromatid breaks, gaps and sub-chromatid aberrations were the most common chromosomal abnormalities. A significant and dose-dependent decrease $(p<0.001)$ in the frequency of mitoses was detected for the treatment with fotemustine $(r=-0.491, p<0.001)$. The results on the induction of SCEs and HFCs (high frequency SCE cells) at all dose groups are shown in Tables III and IV. Specifically, induction of SCEs is significantly increased by fotemustine compared with the negative control $(p<0.0005)$. This effect of fotemustine was further found to be dose-dependent ( $r=$ 0.903, $p<0.001$ ).

Vinorelbine only increased the numerical CAs significantly $(p<0.001)$ and this effect was found as dose-dependent $(r=0.757, p<0.0005$, Table V). Although vinorelbine slightly increased the structural CA frequency, this increase was not statistically significant $(p>0.05)$. A significant increase in the MI values was observed in all doses of vinorelbine $(p<0.001)$.

Induction of SCEs is significantly $(p<0.001)$ and dose-dependently increased by vinorelbine compared with the negative control $(r=0.823$, $p<0.001)$ as seen in Tables III and VI.

Two-way ANOVA was done to determine different interindividual and gender-specific genotoxic responses to fotemustine and vinorelbine. For this aim, we used the CA, SCE and MI data resulting from fotemustine and vinorelbine treatment in each donor and gender. Individual responses to fotemustine were analyzed utilizing the

Table I. Frequencies of chromosome aberrations and mitotic index in cultured human lymphocytes treated with fotemustine and its statistical evaluations.

\begin{tabular}{|c|c|c|c|c|c|c|c|c|c|c|c|c|c|}
\hline \multirow{2}{*}{$\begin{array}{l}\text { Test } \\
\text { substance }\end{array}$} & \multirow{2}{*}{$\begin{array}{c}\text { Dose } \\
{[\mu \mathrm{g} / \mathrm{ml}]}\end{array}$} & \multirow{2}{*}{$\begin{array}{l}\text { Mitotic } \\
\text { index }\end{array}$} & \multicolumn{9}{|c|}{ Total abnormalities ${ }^{\mathrm{a}}$} & \multirow[t]{2}{*}{ TCA/Cell ${ }^{\mathrm{b}}$} & \multirow{2}{*}{$\begin{array}{c}\mathrm{TCA}-(\mathrm{G}+\mathrm{P}) / \\
\text { Cell }^{\mathrm{b}}\end{array}$} \\
\hline & & & $\mathrm{CB}$ & ICB & $\mathrm{G}$ & SCA & $\mathrm{E}$ & $\mathrm{ACF}$ & $\mathrm{P}$ & DS & $\mathrm{R}$ & & \\
\hline Distilled water & & $5.45 \pm 1.33$ & 17 & 4 & 50 & 0 & 1 & 0 & 0 & 0 & 0 & $0.07 \pm 0.03$ & $0.02 \pm 0.02$ \\
\hline \multirow[t]{3}{*}{ Fotemustine } & 2 & $4.99 \pm 1.51$ & 211 & 52 & 237 & 111 & 26 & 2 & 2 & 0 & 0 & $0.63 \pm 0.18 * * *$ & $0.39 \pm 0.12 * * *$ \\
\hline & 4 & $4.45 \pm 1.19$ & 369 & 135 & 331 & 173 & 103 & 2 & 2 & 2 & 0 & $1.11 \pm 0.24 * * *$ & $0.79 \pm 0.21 * * *$ \\
\hline & 8 & $3.58 \pm 0.96 * *$ & 565 & 251 & 381 & 200 & 205 & 4 & 4 & 0 & 0 & $1.59 \pm 0.47 * * *$ & $1.21 \pm 0.36^{* * *}$ \\
\hline Mitomycine-C & 0.25 & $2.15 \pm 0.19$ & 125 & 76 & 37 & 4 & 32 & 37 & 7 & 5 & 2 & $2.13 \pm 0.86$ & $1.84 \pm 0.73$ \\
\hline
\end{tabular}

a A total of 4000 cells was recorded for analysis of chromosome aberrations. CB, chromatid break; ICB, iso-chromatid break; G, gap; SCA, sub-chromatid aberrations; E, exchange; ACF, A-centric fragments; P, pulverization; DS, dicentric chromosome; $\mathrm{R}$, ring chromosome.

b TCA, total chromosome aberrations; TCA $-(\mathrm{G}+\mathrm{P})$, total chromosome aberrations excluding gaps and pulverizations.

$* * p<0.001 ; * * * p<0.0005$.

Means \pm standard deviation. 


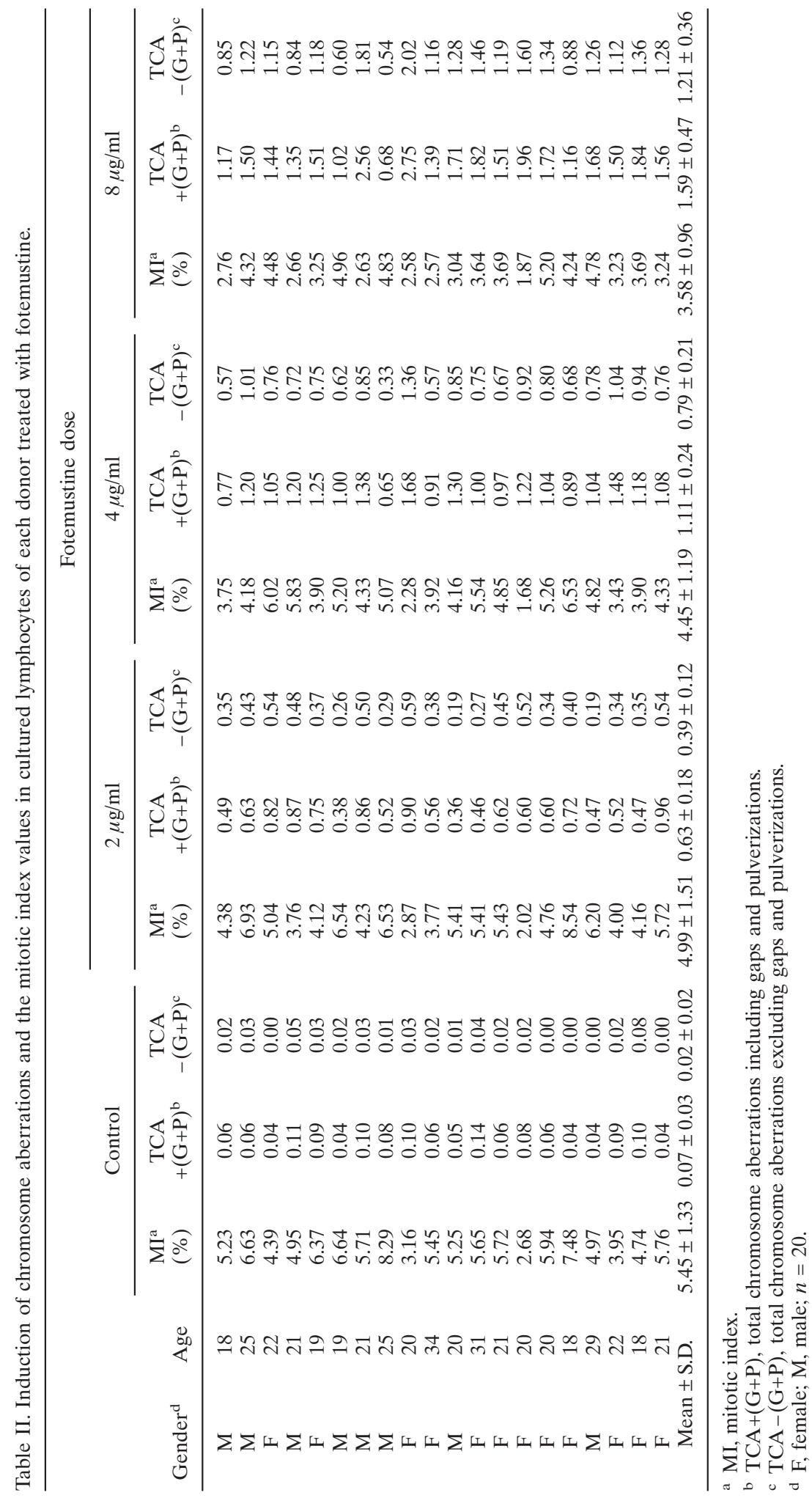




\begin{tabular}{llrrl}
\hline Test substance & $\begin{array}{c}\text { Dose } \\
{[\mu \mathrm{g} / \mathrm{ml}]}\end{array}$ & $\begin{array}{c}\text { Min.-Max. } \\
\text { SCE }^{\mathrm{a}}\end{array}$ & SCE/Cell & HFC $^{\mathrm{b}}$ \\
\hline Control & & $0-10$ & $3.08 \pm 0.81$ & $0.00 \pm 0.00$ \\
Fotemustine & 2 & $6-41$ & $18.46 \pm 6.65^{* * *}$ & $0.00 \pm 0.00$ \\
& 4 & $14-83$ & $39.48 \pm 12.28^{* * *}$ & $0.00 \pm 0.00$ \\
Control & 8 & $32-118$ & $66.10 \pm 17.64^{* * *}$ & $0.07 \pm 0.15^{*}$ \\
Vinorelbine & 0.5 & $0-10$ & $2.51 \pm 0.93^{* * *}$ & $0.00 \pm 0.00$ \\
& 1 & $0-16$ & $4.97 \pm 1.80^{* * * *}$ & $0.00 \pm 0.00$ \\
Mitomycine-C & 2 & $4-18$ & $7.23 \pm 2.01^{* * *}$ & $0.00 \pm 0.00$ \\
& 0.25 & $40-115$ & $73.04 \pm 7.03$ & $0.01 \pm 0.04$ \\
\hline
\end{tabular}

\begin{tabular}{|c|c|c|c|c|c|c|}
\hline \multirow[b]{2}{*}{ Donor } & \multirow[b]{2}{*}{ Gender $^{\mathrm{a}}$} & \multirow[b]{2}{*}{ Age } & \multirow[b]{2}{*}{ Control } & \multicolumn{3}{|c|}{ Fotemustine dose } \\
\hline & & & & $2 \mu \mathrm{g} / \mathrm{ml}$ & $4 \mu \mathrm{g} / \mathrm{ml}$ & $8 \mu \mathrm{g} / \mathrm{ml}$ \\
\hline 1 & M & 18 & 2.12 & 12.46 & 30.80 & 47.72 \\
\hline 2 & M & 25 & 4.30 & 27.24 & 62.76 & 72.46 \\
\hline 3 & $\mathrm{~F}$ & 22 & 2.80 & 23.14 & 36.00 & 46.94 \\
\hline 4 & M & 21 & 3.50 & 15.94 & 37.56 & 84.38 \\
\hline 5 & $\mathrm{~F}$ & 19 & 3.10 & 14.24 & 32.08 & 43.66 \\
\hline 6 & M & 19 & 3.88 & 13.68 & 26.08 & 48.36 \\
\hline 7 & M & 21 & 3.20 & 12.36 & 35.64 & 50.52 \\
\hline 8 & M & 25 & 3.12 & 12.56 & 23.56 & 59.38 \\
\hline 9 & $\mathrm{~F}$ & 20 & 2.62 & 18.28 & 38.28 & 77.52 \\
\hline 10 & $\mathrm{~F}$ & 34 & 2.32 & 16.06 & 41.56 & 92.60 \\
\hline 11 & M & 20 & 2.50 & 10.40 & 26.06 & 38.88 \\
\hline 12 & $\mathrm{~F}$ & 31 & 3.68 & 15.08 & 36.00 & 59.24 \\
\hline 13 & $\mathrm{~F}$ & 21 & 2.96 & 20.20 & 38.04 & 57.26 \\
\hline 14 & $\mathrm{~F}$ & 20 & 3.20 & 35.32 & 60.24 & 86.13 \\
\hline 15 & $\mathrm{~F}$ & 20 & 5.33 & 16.76 & 40.28 & 90.24 \\
\hline 16 & $\mathrm{~F}$ & 18 & 1.80 & 12.56 & 35.32 & 57.26 \\
\hline 17 & M & 29 & 2.76 & 20.88 & 35.84 & 65.66 \\
\hline 18 & $\mathrm{~F}$ & 22 & 2.64 & 25.76 & 51.56 & 78.24 \\
\hline 19 & $\mathrm{~F}$ & 18 & 2.36 & 16.72 & 32.80 & 71.24 \\
\hline 20 & $\mathrm{~F}$ & 21 & 3.32 & 29.32 & 69.08 & 94.28 \\
\hline
\end{tabular}

Table III. Effects of fotemustine and vinorelbine on SCE induction and HFC proportions in human lymphocyte cultures. SCE/Cell and HFC values are percentage averages. (Each treated group $n=20$; means \pm standard deviation.)

a SCE, sister chromatid exchange.

b SCE/Cell, sister chromatid exchange per cell.

c HFC, high frequency SCE cell. $* p<0.05$; *** $p<0.0005$.

Table IV. Induction of sister chromatid exchanges per cell in cultured lymphocytes of each donor treated with fotemustine. total aberrations data yielding significantly different responses among individuals $(F=2.715$, $p<0.001)$. Likewise, a significant difference was found among individuals with respect to the results of total aberrations excluding gaps and pulverizations $(F=2.802, p<0$. 001). When we compared the total aberrations between genders we did not find any significantly different overall response to fotemustine $(F=2.486, p>0.05)$. However, each gender exhibited a different response when we excluded the gaps and pulverizations from the total aberration data $(F=5.855$, $p<0.05)$.

We used numerical CA values for the comparison of interindividual variation differences following vinorelbine treatment. Statistically significant differences in the numerical CAs in each donor were found $(F=1.949, p<0.05)$. However, there was no significant difference between two genders according to numerical CA values.

Moreover, interindividual variations in the MI values were significantly different within the fotemustine treatments $(F=8.987, p<0.001)$. Additionally, significantly different MI responses in each gender were also found $(F=4.262, p<0.05)$.

Although individuals showed different MI responses to vinorelbine $(F=4.019, p<0.001)$, we did not found any significant variation among male and female donors according to $\mathrm{MI}$ values $(F=0.140, p>0.05)$.

Highly significant variations in the SCE response to fotemustine were obtained among individuals $(F=3.467, p<0.001)$ and also in each gender $(F=6.250, p<0.05)$. Similarly, with re- 
spect to the SCE response to vinorelbine, there was a significant interindividual variation $(F=$ 7.667, $p<0.001)$. Lastly, a significant gender-specific SCE response to vinorelbine was evident ( $F=$ $15.176, p<0.001)$.

\section{Discussion and Conclusion}

Chromosome aberrations (Natarajan, 2002; Lopez-Nigro et al., 2003), SCEs, HFCs (Wolff, 1982) and aneuploidy (Kirsch-Volders and Fenech, 2001) have long been recognized to be important biomarkers of human exposure to ionizing radiation and genotoxic chemicals, and sensitive parameters for describing induced DNA and spindle damage. These events can lead to the loss of chromosomal material at mitosis and may lead to cell death through loss of chromosomal DNA (Tucker and Preston, 1996). In this investigation, we assessed the induction of CAs, SCEs and aneuploidy, and its cytotoxic effect using the MI parameter in human lymphocytes in vitro. The results of our study indicated that fotemustine caused a significant increase in the SCE frequency and CAs in human lymphocytes. These effects of fotemustine may be cross-links in DNA as an alkylating agent. It was shown that vinorelbine produced hypo- and hyperploidy. These findings are in agreement with those observed in previous studies in which aneuploidy was determined using micronucleus assays with fluorescence in in situ hybridization (GonzalezCid et al., 1999).

The MI was decreased significantly by fotemustine treatment. This effect of fotemustine may cause cell death and DNA damage. The mitotic arresting activity of vinorelbine was also manifested in a high number of cells blocked at metaphase, in that substantial increase in the MI was observed in all tests. Similar results were also found in Chinese hamster cells (Rainaldi et al., 1987) and in mice exposed to Vinca alkaloids or other antimitotic drugs (Pacchierotti et al., 1991).

In the past decade, inter-individual and genderrelated variability in drug response have received much attention. In this study, we have set out to determine these variabilities in genotoxic response to fotemustine and vinorelbine. We found statistically significant differences in the induction of CAs, SCEs, aneuploidy cells and MI among individuals for fotemustine and vinorelbine. These different genotoxic responses were also determined between genders. Individual and gender-related 


\begin{tabular}{|c|c|c|c|c|c|c|c|}
\hline \multirow[b]{2}{*}{ Donor } & \multirow[b]{2}{*}{ Gender $^{\mathrm{a}}$} & \multirow[b]{2}{*}{ Age } & \multirow[b]{2}{*}{ Control } & \multicolumn{3}{|c|}{ Vinorelbine doses } & \multirow{2}{*}{$\begin{array}{l}\text { Table VI. Induction of } \\
\text { exchanges per cell in } \\
\text { cytes from each donor } \\
\text { orelbine. }\end{array}$} \\
\hline & & & & $0.5 \mu \mathrm{g} / \mathrm{ml}$ & $1 \mu \mathrm{g} / \mathrm{ml}$ & $2 \mu \mathrm{g} / \mathrm{ml}$ & \\
\hline 1 & $\mathrm{~F}$ & 25 & 2.43 & 5.91 & 9.00 & 11.56 & \\
\hline 2 & $\mathrm{~F}$ & 23 & 3.87 & 8.96 & 12.02 & 16.87 & \\
\hline 3 & $\mathrm{~F}$ & 22 & 2.78 & 6.65 & 8.83 & 8.63 & \\
\hline 4 & $\mathrm{~F}$ & 22 & 3.12 & 5.84 & 6.87 & 9.31 & \\
\hline 5 & M & 25 & 1.06 & 2.43 & 3.75 & 6.18 & \\
\hline 6 & M & 27 & 0.97 & 2.64 & 5.07 & 9.80 & \\
\hline 7 & $\mathrm{~F}$ & 19 & 2.04 & 4.12 & 4.24 & 6.89 & \\
\hline 8 & $\mathrm{~F}$ & 22 & 2.67 & 5.14 & 7.26 & 8.20 & \\
\hline 9 & $\mathrm{~F}$ & 22 & 2.85 & 4.57 & 6.80 & 9.20 & \\
\hline 10 & $\mathrm{~F}$ & 21 & 2.54 & 6.09 & 9.32 & 13.43 & \\
\hline 11 & $\mathrm{~F}$ & 22 & 2.44 & 4.21 & 7.54 & 10.57 & \\
\hline 12 & $\mathrm{~F}$ & 21 & 2.87 & 5.50 & 6.89 & 7.46 & \\
\hline 13 & $\mathrm{~F}$ & 22 & 3.41 & 6.19 & 8.74 & 10.13 & \\
\hline 14 & M & 29 & 2.76 & 4.08 & 5.52 & 7.59 & \\
\hline 15 & $\mathrm{~F}$ & 31 & 3.40 & 4.94 & 6.82 & 7.66 & \\
\hline 16 & M & 28 & 0.52 & 1.68 & 4.78 & 9.11 & \\
\hline 17 & $\mathrm{~F}$ & 21 & 2.56 & 4.85 & 6.89 & 10.13 & \\
\hline 18 & M & 26 & 1.20 & 2.29 & 6.86 & 9.47 & \\
\hline 19 & $\mathrm{~F}$ & 20 & 3.74 & 6.48 & 7.70 & 9.02 & \\
\hline 20 & M & 40 & 3.04 & 6.82 & 9.64 & 11.36 & \\
\hline
\end{tabular}

variations can be caused by genetic polymorphisms, age and even gender associated with hormonal function (Aldridge et al., 2003).

Many chemotherapeutic drugs have unintentional side effects during the treatment of patients and on the health-care personnel exposed chronically to these drugs. However, such favorable survival rate brings additional concern about the long-term adverse effects of chemotherapy, markedly on fertility and in the incidence of secondary malignancies (Tiburi et al., 2002; Terracini et al., 1987). Therefore, it is essential that effective anticancer drugs should be tested not only for their cytotoxic potential but also for their ability to disturb genomic integrity, in order to render a deeper understanding of the potential risks related to exposing in anytime. Different individual and gender responses to fotemustine and vinorelbine demonstrated may also be indicative of a dose selection in chemotherapy.

\section{Acknowledgements}

This investigation was supported by Scientific Researches Directorship, The Uludağ University (project no: 2002/52). The authors thank Dr. Jason Cooley for the revision of the English.
Aldridge J. E., Gibbons J. A., Flaherty M. M., Kreider M. L., Romano J. A., and Lewin A. D. (2003), Heterogeneity of toxicant response: Sources of human variability. Toxicol. Sci. 76, 3-20.

Ashby J., Vogel E. W., Tinwell H., Callander R. D., and Shuker D. E. G. (1993), Mutagenicity to Salmonella, Drosophila and mouse bone marrow of the human antineoplastic agent fotemustine: prediction of carcinogenic potency. Mutat. Res. 286, 101-109.

Bolzan A. D. and Bianchi M. S. (2002), Chromosomal response of human lymphocytes to streptozotocin. Mutat. Res. 503, 63-68.
Bunn A. Jr and Kelly K. (1998), New chemotherapeutic agents prolong survival and improve quality of life in non-small cell lung cancer: a review of the literature and future directions. Clin. Cancer Res. 4, 1087-1100.

Gander M., Leyuraz S., Decosterd L., Bonzanti M., Shen F., Lienard D., Perey L., Colella G., Biollaz J., Lejeune F., Yarosh D., Belanich M., and D'incalci M. (1999), Sequential administration of temozolomid and fotemustine: Depletion of $\mathrm{O}^{6}$-alkylguanine-DNA transferase in blood lymphocytes and in tumors. Ann. Oncol. 10, $831-838$. 
Gonzalez-Cid M., Cuello M. T., and Larripa I. (1997), Vinorelbine: cell cycle kinetics and differential sensitivity of human lymphocyte subpopulations. Toxicol. Lett. 93, 171-176.

Gonzalez-Cid M., Cuello M. T., and Larripa I. (1999), Comparison of the aneugenic effect of vinorelbine and vincristine in cultured human lymphocytes. Mutagenesis 14, 63-66.

Ingelman-Sundberg M. (2001), Genetic susceptibility to adverse effects of drugs and environmental toxicants. The role of the CYP family of enzymes. Mutat. Res. 482, 11-19.

Kirsch-Volders M. and Fenech M. (2001), Inclusion of micronuclei in non-divided mononuclear lymphocytes and necrosis/apoptosis may provide a more comprehensive cytokinesis block micronucleus assay for biomonitoring purposes. Mutagenesis 16, 51-58.

Lopez-Nigro M. M., Palermo A. M., Mudry M. D., and Carballo M. A. (2003), Cytogenetic evaluation of two nitroimidazole derivatives. Toxicol. in vitro 17, 35-40.

Margison G. P. and Santibanez-Koref M. F. (2002), O ${ }^{6}$ Alkylguanine-DNA alkyltransferase: role in carcinogenesis and chemotherapy. BioEssays 24, 255-266.

Marzolini C., Decosterd L. A., Shen F., Gander M., Leyuraz S., Bauer J., Buclin T., Biollaz J., and Lejeune F. (1998), Pharmacokinetics of temozolomide in association with fotemustine in malignant melanoma and malignant glioma patients: comparison of oral, intravenous and hepatic intra arterial administration. Cancer Chemother. Pharmacol. 42, 433-440.

Natarajan A. T. (2002), Chromosome aberrations: past, present and future. Mutat. Res. 504, 3-16.

Ngan V. K., Bellman K., Hill B. T., Wilson L., and Jordan M. A (2001), Mechanism of mitotic block and inhibition of cell proliferation by the semisynthetic Vinca alkaloids vinorelbine and its newer derivative vinflunine. Mol. Pharmacol. 60, 225-232.

Pacchierotti F., Bassani B., Leopardi P., and Zijno A. (1991), Origin of aneuploidy in relation to disturbances of cell-cycle progression. II: Cytogenetic analysis of various parameters in mouse bone marrow cells after colchicines or hydroquinone treatment. Mutagenesis 6, 307-311.

Parry P. and Wolf S. (1974), New Giemsa method for differential staining of sister chromatids. Nature 251, $156-158$.

Rainaldi G., Flori L., Colella C. M., Mariani T., Piras A., Simi S., and Simili M. (1987), Analyses by BrUdRlabelling technique of induced aneuploidy in mammalian cells culture. Mutat. Res. 177, 255-260.

Sbrana I., Disibio A., Lomi A., and Scarcelli V. (1993), C-Mitosis and numerical chromosome aberration analyses in human lymphocytes: 10 known or suspected spindle poisons. Mutat. Res. 287, 57-70.

Terracini B., Pastore G., Zurlo M. G., Masera G., Fussati-Bellani F., Castello M., Tamaro P., Massolo F., Rosati D., and Biddan P. F. (1987), Late deaths and second primary malignancies among long-term survivors of childhood cancer: an Italian multi-centre study. Eur. J. Cancer Clin. Oncol. 23, 499-504.

Tiburi M., Reguly M. L., Schwartsmann G., Cunha K. S., Lehmann M., and de Andrade H. H. R. (2002), Comparative genotoxic effect of vincristine, vinblastine and vinorelbine in somatic cells of Drosophila melanogaster. Mutat. Res. 519, 141-149.

Tucker J. D. and Preston R. J. (1996), Chromosome aberrations, micronuclei, aneuploidy, sister chromatid exchange and cancer risk assessment. Mutat. Res. 365, $147-159$.

Vermeulen N. P. E., Commandeur J. N. M., Groot E. J., Wormhoudt L. W., Ramnatshing S., Li Q. J., and Brakenhoff J. P. G. (1998), Toxicicty of fotemustine in rat hepatocytes and mechanism-based protection against it. Chem. Biol. Interact. 110, 139-158.

Winum J. Y., Bouissière J. L., Passagne I., Evrard A., Montero V., Cuq P., and Montero J. L. (2003), Synthesis and biological evaluation of fotemustine analogues on human melanoma cell lines. Eur. J. Med. Chem. 38, 319-324.

Wolff S. (ed.) (1982), Sister chromatid exchange. John Wiley and Sons, New York, NY.

Zhou X. J. and Rahmani R. (1992), Preclinical and clinical pharmacology of Vinca alkaloids. Drugs 44, 1-16.

Nachdruck - auch auszugsweise - nur mit schriftlicher Genehmigung des Verlages gestattet Satz und Druck: AZ Druck und Datentechnik GmbH, Kempten 